\title{
Applications for mobile devices informing about threats
}

\author{
Norbert Tuśnio ${ }^{1, *}$ \\ ${ }^{1}$ The Main School of Fire Service, Faculty of Fire Safety Engineering, 52/54 Slowackiego St., 01-629 \\ Warsaw, Poland
}

\begin{abstract}
Following article contains a description of selected applications for mobile devices, such as smartphones or tablets, which tasks are to inform the public about hazards, as well as calling for help. The focus was on software widely available in online app store (Google Play), and due to the imperfections of the programs mentioned, it was decided to develop own application called "Rescue Application Volunteer". Its main purpose and functionality covers help summoning for oneself and other people, also marking places on map where e.g. fire is starting or local threat is arising. Various solutions of these problems were given and issues related to the protection of personal data in this type of applications were discussed.
\end{abstract}

\section{Introduction}

Many applications for mobile devices have been created in the world for calling medical help and alerting volunteer services [1-3]. The purpose of such projects is to create a mobile application that informs users about the existence of a sudden threat to health and life in persons in a public place, thus increasing the likelihood of effective first aid before the arrival of emergency services. Additionally, users of such an application can provide information about extraordinary events noticed: fires, disasters, accidents, etc. The article is about introducing author's own application and comparing it against existing solutions. The application proposed by the author is able to supplement the offer of solutions currently functioning on the market by increasing the number of useful information about the case. They will allow you to provide the appropriate first aid and to forward to the dispatcher the emergency number of the most important data about the incident. This application does not require the passage of complicated legal procedures under the Data Protection Directive, because the information is passed between users of the application who have given their consent.

\section{Rescue Application (Emergency Call)}

The purpose of the Rescue Application is reporting accidents or getting lost in the mountains, as well as incidents at water reservoirs (e.g. seeing a drowning person). Stress in

\footnotetext{
* Corresponding author: ntusnio@sgsp.edu.pl
} 
such situations can causes lack of orientation and problems with remembering emergency numbers. The most important functions of the Rescue Application are:

- calling for help (reporting accidents) - by phoning rescue services in Poland, in mountain areas and by the water (GOPR Mountain Volunteer Search and Rescue, TOPR Tatra Volunteer Search and Rescue, WOPR Water Volunteer Search and Rescue and MOPR Masuria Volunteer Search and Rescue). When help is needed, the application dials the integrated number automatically and calls the right rescue services

- localizing the person calling for help - sending the information with precise location (up to 3 meters) to the chosen rescue service automatically. The location is sent in a text message during the phone call.

The Rescue Application, the screen of which has been shown on Figure 1, is the only application approved by voluntary rescue services in Poland, which has been included in the accident reporting system. The ticket is accepted upon a phone call [4].

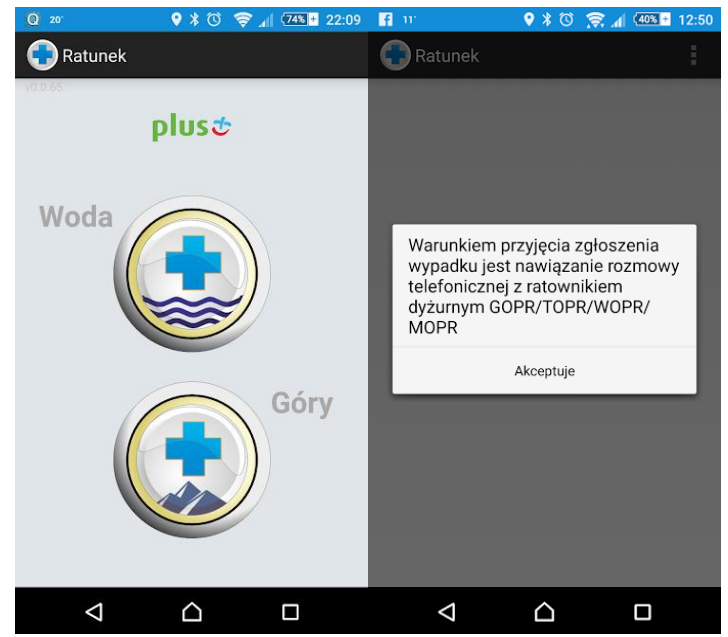

Fig. 1. Rescue Application screen.

\section{RSO - Regional Warning System}

The Regional Warning System (pol. Regionalny System Ostrzegania, RSO) is a free mobile application developed by Ministry of Interior and Administration in cooperation with TVP Polish Television. The application is part of a wider service informing the society about dangers in Poland by means of various information channels: voivodship internet sites, news tickers and teletext in TV-sets receiving DVB ground-based signal and a hbbtv hybrid internet TV.

The WCZK Voivodship Centres of Crisis Management, which are subordinate to voivodes, convey messages about various dangers to users of the RSO mobile application.

Depending on their significance they can be informative notifications and:

- warnings - they convey a potential danger, local problems or warnings by IMGW (Institute of Meteorology and Water Management (such information appear on news tickers of TV-sets receiving DVB signal on TVP regional TV)

- alarm notifications - they convey a hazard level, which needs to be received by a wider group of inhabitants (WCZK starts informing on regional level through PUSH channel and through information tickers on TV-sets receiving a DVB signal on TVP channels). 
The following types of notifications are sent within RSO: meteorological, hydrological, vehicular, concerning water levels and general notifications. Users of the application have the possibility to choose the type of notification and regions (voivodships) from which they would like to receive notifications. Besides, when the geolocation function is activated, alarm notifications and messages from the current user location are conveyed.

Users can also use a rich library of guidebooks explaining how to behave in crisis or danger. They are formulated in an easy and understandable way, updated on regular basis and made available for users without the need to update the mobile application. Thus, RSO has an educational function in the scope of recommended behaviour in crisis situations among society [5].

An example of application screens are presented on Figure 2.

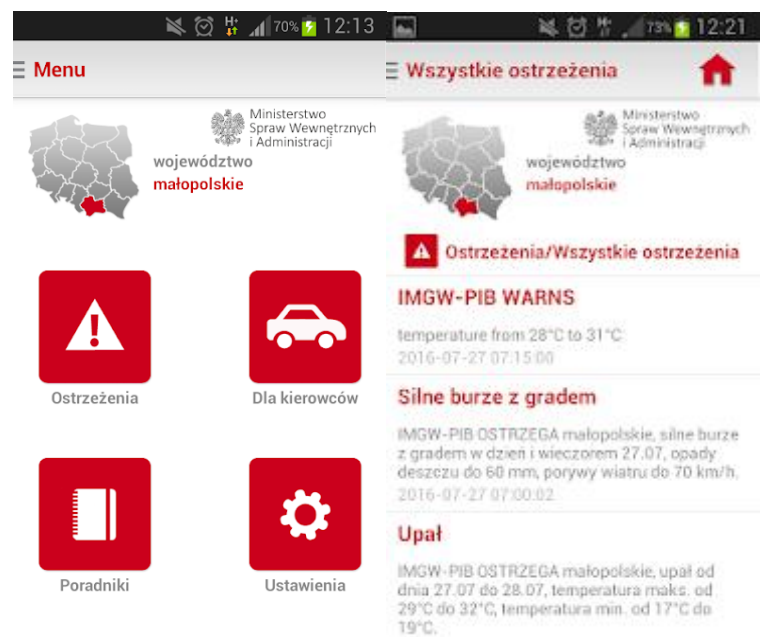

Fig. 2. RSO Application screens - Regional Warning System.

\section{Domestic Map of Security Threats}

The access to the Domestic Map of security threats is accessible via the following internet site (https://mapy.eoportal.gov/iMapLite/KMZBPublic.html), as well as from the mobile application. Its development was initiated by Police in cooperation with the Head Office of Geodesy and Cartography. The aim was to raise the sense of security among society.

This tool was developed by institutions co-responsible for providing safety and public order. Its aim is to identify information about the type and scope of dangers clearly and credibly and to convey it to local societies. This identification occurs in cooperation with society (under the service rules only one ticket can be sent from one IP address per day). The Map of security threats is to be considered as an important part of public order management process, accomplished in interinstitutional and social partnership. It can also be used for optimal allocation of equipment and staff resources of services, especially for deciding on creating new police stations and checkpoints.

The Domestic Map of security threats bases on information catalogued in 3 dimensions:

- information gathered in police IT systems

- acquired from society directly from citizens, from representatives of local selfgovernment, non-governmental organizations etc. or public debates devoted to public order

- obtained from citizens (internet users) utilizing an information exchange platform.

The data presented on maps takes into account some categories of crime, violation, as well as dangers, which negatively affect the subjective sense of security of the citizens. 
They include: vandalism, homelessness, unwatched beaches and dangerous places by the water (frequent drownings), wild dumping sites, gatherings of the juvenile susceptible to demoralization, poaching, illegal logging, unreported car races, parking violation, unwatched railway tracks passages and crossings, faulty road infrastructure, damaging greenery, driving quads in the forests, exceeding speed limits, drinking alcohol in public places, using dopes, aggressive dogs, burning grass, road incidents with forest animals, animal abuse, faulty road organization or mendicancy [6].

Application screens are presented on Figure 3.

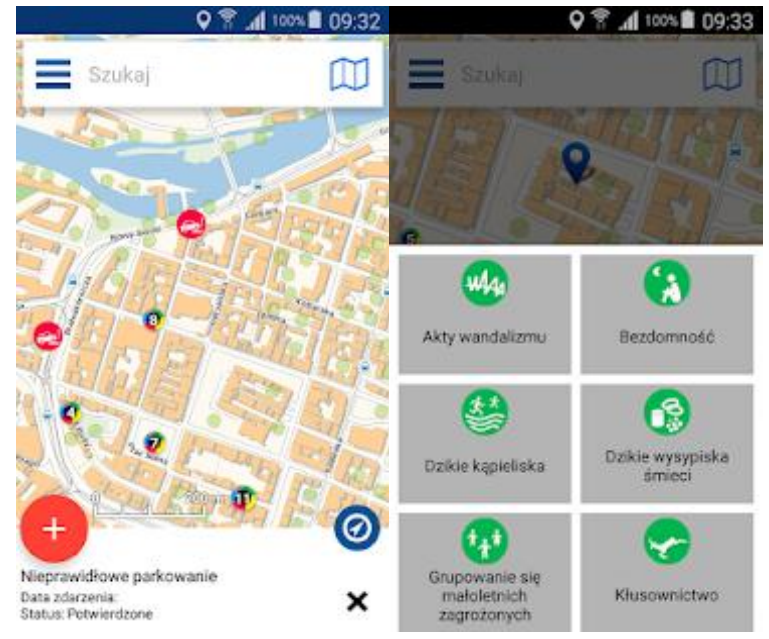

Fig. 3. Geoportal Mobile application screens (Domestic Map of Security Threats).

\section{I am near Application}

A slightly different aim of another project was a mobile application project, which would enable to inform users about sudden medical hazards and dangers to life in people in public places and thereby increasing chances of providing first aid before the arrival of rescue services (e.g. with the use of automatic defibrillator). From the technical side, the application is ready, unfortunately the current legal interpretation does not allow for its implementation.

The project accomplishment based on creating and implementing a proprietary "I am near" application, which enables to send information by the emergency number 112 (optionally by a dispatcher of another rescue services) to end users, who agreed to install the application on their mobile device voluntarily. Their contribution in the project (in case of emergency or medical hazard in people in public places) means a potential consent to get to a given place and take necessary means to give first aid.

Emergency number operators inform users in the distance closer than $1 \mathrm{~km}$ about the need to provide help to an unconscious person, who can have a sudden circulatory arrest in a public place. They do it by entering the address in the dispatch bar of the "I am near" application. Ultimately, the dispatch bar should be integrated with the dispatch software used in the Rescue Centres. Users, who confirm obtaining the signal, are sent information about the best way to get to the person in need in order to shorten the time of reaching the destination point.

"I am near" application is dedicated to all users willing and able to provide first aid. The system gathers neither personal data nor the location history of users. Is will also enable getting information about social willingness to get involved when giving first aid is needed. 
Implying its future development it gives the possibility of gaining knowledge and procedures about handling sufferers on incident site by all people who are interested.

Once implemented, the application will constitute an invaluable support for rescue systems. It will contribute to the increase of security of citizens, it has also a great potential to improve survival rate in sudden circulatory arrests and other sudden health hazards. The concept of creating the application is a natural consequence and continuation of already existing projects, like AED The Net of defibrillators of Krakow "Impulse of life" [7].

\section{Volunteer Rescue Application}

The Volunteer Rescue Application has been developed by the author of this article and tested in the cooperation with students from the scientific circle from SGSP (The Main School of Fire Service). Simple web mechanisms, which enable to develop the application form jigsaw puzzles constituting commands, which serve events (like MIT App Inventor, Thunkable), have been used. The application cooperates well with google maps (the best access road is shown immediately) and with GPS mobile phone sensor.

The first application screen enables to report an incident, to detect it in a given radius, as well as to decide on making for the accident site in order to provide help (the amount of volunteers approaching the same location is posted online).

The second screen gives the opportunity to report an incident and their amount has been limited to the minimum (to the number of 9), to avoid the need of reading a lot of text in a stressful situation.

The possible incidents that trigger sudden medical hazards are:

1. Calling for help on behalf of another person, who is:

a) conscious

b) unconscious

c) in danger of drowning (incidents by the water in the summer or in the winter in case of ice breakage) or hypothermia (e.g. getting lost in the mountains).

2. Reporting the most common dangerous incidents like:

a) fire or explosion

b) road accident

c) incidents caused by forces of nature.

3. Calling for help for one's own, in case of:

a) feeling bad

b) getting lost

c) being threatened by another people, or connected with unlawful acts.

The author of the application thinks that the choice of 9 available cases enables to create a wider image of the incident, basing on the combination of available options. As an example, the consequences of a building collapse can be signalized as reporting dangerous incident in the form of explosion (option 2a) and adding injured people: conscious (option 1a) or unconscious (option 1b). A communication incident can be treated similarly by adding the inured likewise. Such a universal possibility to create the image of the incident is a good point to accomplish the idea of synoptic board of the protected area for rescue services.

The next application screen gives the possibility of entering one's qualifications to the database. Especially of importance can be the ability to provide first aid by a volunteer and the level of these qualifications can vary (e.g. first aid course graduation). A similar value has the ability to rescue drowning people or a driving license of a higher category. In order to develop the application, it is essential to extend the list of entered qualifications and to create a system of verifying them. 
The third application screen enables to open a chat between volunteers, which takes place on the last (fourth) screen where they can exchange detailed information like their location, current situation or telephone contact.

In case of further development of the application and increase of the number of users, there might be a need to separate chats for a given incident (to create channels for internal use).

The screens of Volunteer Rescue Application have been shown on Figure 4.

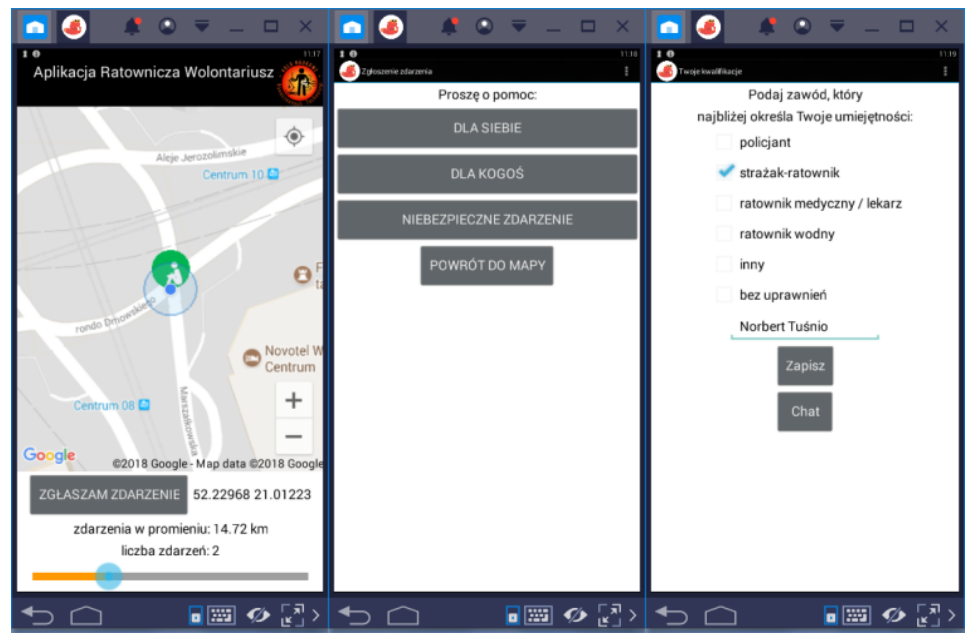

Fig. 4. Volunteer Rescue Application screens.

The application is directed to individuals, not institutions. Her idea is to support volunteering related to rescue and mutual help. It is a wider proposal than "I am near" and "Staying Alive" applications, which only concerns cardiological problems. It differs from "Domestic Map of Security Threats" and "Regional Warning System" in its ability to take action, and not only to provide information to relevant services. "Rescue Application (Emergency Call)" is dedicated to providing information only in two specific cases of events in mountain areas and water bodies. The proposed application covers a much larger number of threats and is interactive.

\section{Summary}

The article describes open-access applications for mobile devices, which enable informing the society about dangers and in special cases calling for professional or voluntary help on the condition that the managing organizations reported their readiness.

The Rescue Application can be used in case of dangers by the water or in the mountains. It is necessary to activate GPS function to start the application. A certain impediment of the application is the requirement to get in touch with the rescuers, without which the ticket is invalid. Moreover, opinions posted in Google Store show that there are some difficulties with server connection.

The RSO Regional Warning System is a mobile application, the development of which was initiated by Ministry of Interior and Administration in the cooperation with Polish Television TVP. It is an innovative solution, the aim of which is to inform society about dangers. Its next function is to educate through guidebooks explaining how to act in crisis situations. The RSO application allows to:

- browse warnings about extraordinary situations in the whole country in the following categories: meteorological, hydrological, vehicular, general 
- water levels in rivers in whole Poland

- access to a knowledge base in the form of guidebooks teaching how to act in crisis situations.

The warnings come from the voivodship centres of crisis management, which receive information about dangers e.g. from Institute of Meteorology and Water Management National Research Institute or General Directorate for National Roads and Motorways.

The new version of the Regional Warning System (RSO) assumes alert of imminent danger only to persons staying on the affected area.

Another database described in the article was The Domestic Map of Security Threats. It is not a dynamic application informing about sudden dangers related to the sufferers who need help, but it informs abut some inconveniencies in a certain area. That tiny scope of matters covered in the application opens to doubt, because they are classified not as crimes but as violation e.g. traffic violation which could as well be handled by city guard.

"I am near" application may be very useful in rescuing people's lives. It informs people (volunteers) who are in the nearest surrounding about a sudden danger to health and life. Its authors state that it is already technically ready to be used. Both the dispatch panel and the application intended for end user possessing a mobile device like a smartphone or a tablet operating Android system are ready. Unfortunately, a current legal interpretation does not allow to implement the application. Besides, some attempts to get a financial grant from the citizen budget in Krakow went flop.

The idea of developing an own application for people who possess appropriate qualifications and want to provide help (e.g. volunteer fire department) arose from imperfections of the above mentioned programs. The Volunteer Rescue Application functions well on mobile devices, is compatible with google maps, which enables to find the access route to the incident site. Its functions and its possibilities can be fully utilized on the condition that it is used by plenty of active users. At the moment, the application does not use a fast server and its data base is saved on google sheets. It enables to spread information to appropriate rescue services by showing them on the synoptic board of a protected area. If the number of users grows, it should use a more efficient database server and focus on personal data protection. It is also necessary to separate appropriate chat channels between volunteers this way, that chats concerning different incidents does not overlap. Testers of the application suggested introducing the possibility to take pictures on the incident site and to send them to the dispatch centre, which manages the readiness of rescue resources.

The purpose of creating own application was to provide a tool for the local community, which has the characteristic of willingness to help other people. Nowadays, the phenomenon of so-called "social callousness" occurs, which manifests itself in ignoring human suffering, not paying attention to people in need of help, not stopping at places of transport accidents, etc. The application allows to provide help through the minimum commitment that is to call for help.

\section{Conclusions}

1. The analysis of existing foreign applications showed that they are difficult to be implemented in Poland due to their character, but some of their parts can constitute a basis to create a domestic application.

2. The use of rescue application for volunteers in Poland is reasonable only when there are numerous registered users and simultaneously it will serve to inform about dangers and to send data significant to manage rescue resources by dispatch centres of services organizing rescue actions. 
3. The mobile application RSO (Regional Warning System) was employed as the only application to spread the news about storm in Pomerania on the $11^{\text {th }}$ of August 2017 [8]. However, its use could be more effective if there was a possibility to inform when the user changes location automatically e.g. while travelling.

4. The "Volunteer Rescue Application" is a prototype of a system, which could be developed on the condition that the local society finds it of interest and a huge number of volunteers enters data and a fast server will be employed. In case of registration of a huge number of volunteers, the chats have to be channelled so that they concern a given incident.

5. An important matter that conditions impeccable functioning of the rescue applications and applications, with the use of which users can call for help, is the necessity to convey data to particular components of the rescue system of a given country, but also the ability to cooperate between dispatch centres of services and rescue entities.

6. The considered functionality of the application allows to design such solution that the dispatch centres of rescue services could dispatch single volunteers to an incident. This enterprise demands to integrate the dispatch centres in Poland. Besides, this must be preceded by signing a civil law agreement between volunteers ready to help and the operating administrator of rescue system.

7. During application development the analysis of organizational solutions of the binding law regarding personal data protection should be taken into consideration (in Poland RODO, General Data Protection Regulation).

8. Rescue mobile applications used to provide information about threats are quite popular [9-11]. In various regions of the world, they inform or enable to send information about specific threats to the area (eg mudslides, earthquakes, floods, etc.). Since 2001, research has been carried out on a global application dedicated to tourists [12].

\section{References}

1. T.D. Indriasari, K. Anindito, E. Julianto, B. Pangaribuan, iJIM, 11 (2017)

2. U. Meissen and others, CoRe Paper - New Technologies for Crisis Management Proceedings of the $14^{\text {th }}$ ISCRAM Conference, Albi, France (2017)

3. M. Spångmyr, Student thesis series INES no. 294, Lund, Sweden (2014)

4. Rescue - Android application on Google Play https://play.google.com/store/apps/ details?id=com.pagasolutions.emergencycall_pl (access 08.04.2018)

5. Regional Warning System - Android application on Google Play https://play.google.com/store/apps/details?id=mswia.rso (access 08.04.2018)

6. Domestic Map of security threats http://www.policja.pl/pol/mapa-zagrozenbezpiecze/33880,dok.html (access 08.04.2018)

7. Application I am near http://www.jestemblisko.pl/aktualnosci/ (access 16.04.2018)

8. G. Ułan, Why was there no SMS warning before the storms? We asked Polish operators http://antyweb.pl/aplikacja-mobilna-rso-to-na-dzis-jedyny-sposob-naostrzeganie-obywateli-o-zagrozeniach/ (access 10.04.2018)

9. N. Leelawat, L.G. Pee, J. Iijima, International Conference on Mobile Business. 15. Berlin, Germany (2013)

10. D. Alexander, Principles of emergency planning and management (Oxford University Press, New York, USA, 2002)

11. J.T.B. Fajardo, C.M. Oppus, WSEAS Transactions on Communications, 9 (2010)

12. B. Faulkner, Tourism Management, 22 (2001) 